\title{
El perfume del Esposo. Según Gregorio de Nisa en el Comentario al Cantar de los Cantares
}

\section{PRELIMINARES}

El perfume desde la antigüedad ha sido interpretado como signo de la vida divina, y Gregorio lo acoge para introducirlo como clave de comprensión en un orden radicalmente nuevo, a partir de la figura del Esposo.

\section{ANTECEDENTES}

El perfume a partir de su propia naturaleza se constituye como un instrumento de comunicación. Por ello en la experiencia religiosa posee un significado profundo en cuanto el hombre puede entrar en presencia de una fuerza vital proveniente del mundo divino (1). La divinidad perfumada se avecina al hombre como parte de su revelación.

Para comprender su significado simbólico es necesario encuadrarlo en el tema del conocimiento a través de los cinco sentidos. Sentidos por los cuales el hombre percibe sensaciones buenas o malas, agradables o desagradables. Desde la antigüedad la fuente de la sensación agradable fue asociada al mundo de lo divino y lo desagradable al mundo demoníaco. Por ello la divinidad es concebida como luminosa, armoniosa, dulce y perfumada, mientras el reino del mal es tenebroso, ruidoso, amargo y fétido (2).

Los griegos y los romanos veían en el perfume un signo de la teofanía, era conocido como un ungüento que según la medicina los hacía revivir. En el antiguo Egipto el incienso y los aromas inundaban los templos para transportar a los fieles al reino celestial, y el embalsamamiento otorgaba el poder de la vida a quienes estaban muertos (3), incluso los dioses lo respiraban para conservar la inmortalidad (4).

(1) Cf. Meloni P., Il Profumo dell' immortalità. L' interpretazione patristica di Cantico 1, 3. Edizioni Studium-Roma 1975, p. 3.

(2) Ibídem.

(3) Cf. Diccionario Patrístico y de la antigüedad cristiana. II J-Z Institutum Patristicum Augustinianum. Pietro Meloni, dirigido por Angelo Di Berardino Verdad e Imagen 1992, p. 1755.

(4) Ibídem. 
Es el símbolo del aceite perfumado preferido por los neoplatónicos, como difusión misteriosa, suavidad penetrante y de atmósfera invisible que se expande discretamente, sin que la belleza en sí de ese aceite perfumado disminuya o se altere. Se utiliza esta imagen como la esencia, bondad divina, de su efusión en los seres y de inalterable permanencia.

Dionisio el Areopagita hablará más tarde de "la esencia perfumada sobre la inteligencia" (5), de la "belleza perfumada y secreta" (6), de la "fuente del perfume" (7) de "Jesús, el perfume superesencial" (8); la bendición de los santos óleos será para él la revelación lejana de esta cabeza de perfumes que rodea la divina belleza.

El perfume en el hombre libera arcanas sugerencias afectivas (9), en cuanto puede transponer la presencia física del ser amado a un modo más sutil. Posee la capacidad de penetrar en la memoria, en el recuerdo, puesto que con volverlo a oler se es capaz de retener situaciones y personas (10). Por ello se le conoce como embajador del espíritu, ya que cuenta con el poder de evocar la presencia -estando aun ausente- de la persona amada. "Uno de los poderes más sorprendentes del olor es la evocación de la memoria. Una persona que ama conserva la percepción interior del perfume de la persona amada ausente, el hombre que reconoce un perfume por la percepción, revive la sensación del acontecimiento y del mundo evocado" (11). El perfume dice relación a una especie de vibración silenciosa por la que un ser exhala su esencia y quien lo inhala puede percibir el murmullo de su vida oculta (12).

En el mundo antiguo el hombre deseaba sentir la divinidad a través de los cinco sentidos, ver a Dios con los ojos, escuchar su voz con los oídos, tocarlo con las manos, gustarlo con la boca y sentir con la nariz su perfume. Es uno de los primeros instrumentos por el cual el hombre entra en contacto con la realidad humana y gradualmente aspira ascender al conocimiento de la realidad divina (13). Es así como el simbolismo del perfume, tanto en la tradición clásica y cristiana, se ha hecho poseedor de un valor inestimable porque desde tiempos antiguos se le ha relacionado como proximidad de la divinidad (14).

(5) Cf Horn, G., L'Amour Divin, Note sur le mot Eros dans S. Gregoire de Nysse, RAM 6 (1925) 383. Aquí el autor cita a Dionisio el Areopagita.

(6) Ibídem 383

(7) Ibídem.

(8) Ibídem.

(9) Cf. Diccionario Patrístico y de la antigüedad cristiana. II J-Z Institutum Patristicum Augustinianum. Pietro Meloni, dirigido por Angelo Di Berardino. Verdad e Imagen 1992, p. 1755.

(10) Cf. Gonzalo Juan M., A la búsqueda del amado. En: Studium 36 (1996) 182.

(11) Meloni P., Il Profumo dell' immortalità. L'interpretazione patristica di Cantico 1,3. Edizioni Studium-Roma 1975 , p. 6.

(12) Cf. León-Dufour. Vocabulario de teología Bíblica Ed. Herder 1988, p. 687.

(13) Cf. Meloni P., Il Profumo dell' immortalità. L'interpretazione patristica di Cantico 1, 3. Edizioni Studium-Roma 1975, p. 3.

(14) Ibídem IX. 


\section{DINÁMICA DE LOS PERSONAJES DEL CANTAR EN TORNO AL PERFUME}

\section{a. Las doncellas}

En el Cantar se coloca en escena un séquito de jovencitas, crecidas en virtudes, que dirigen su deseo al Esposo en quien nada hay perecedero. "Van en pos del Señor Dios". Ellas aman la belleza de su novio, por la cual se sienten fuertemente atraídas.

Como jóvenes niñas se sienten atraídas por el amor del Esposo incorruptible (15). La causa de este amor es el ungüento perfumante por el cual corren, olvidándose de lo que dejan atrás, lanzándose a lo que está por delante (16). Por ello dicen Corramos, al olor de tus perfumes. Ellas, por su edad juvenil no han alcanzado la vida de perfección, sin embargo corren hacia la meta que les designa el olor perfumante del Esposo (17). También la Perfecta corre al igual que ellas impulsadas por la misma atracción del amor (18) y por el olor que provoca sus perfumes. Por eso te aman las doncellas. ¡Llévame en pos de ti, corramos! (19).

Las doncellas imitarán a la Esposa, ellas saben que es la primera en estar llena de bienes y es digna de conocer los misterios ocultos. Así exclaman: Por ti exhultamos y nos alegramos (20), el gozo en ellas se transforma en una común alegría imitando los amores, por lo cual Cristo es alimento. Esta idea para Gregorio manifiesta el orden eclesial. Donde los primeros instruidos en gracia vieron al Verbo, le siguieron y no le tuvieron para ellos en exclusiva. Transmitiendo la gracia a sus sucesores (21).

Gregorio intuye que a estas jovencitas se las puede comprender como aquellos bautizados cuya característica que les acompaña es estar crecidos en virtudes (22) obedeciendo a la belleza incomprensible y volcándose sobre la persona de Cristo. Reconoce que en esa carrera hacia el buen olor se dirigen hacia el Esposo que es Cristo y con ello desean expresar que al hombre le es permitido de antemano descubrirlo como posibilidad anticipada por la gracia del Espíritu Santo (23). Esta es una economía dinámica gracias a la cual se difunde por este Espíritu y son precisamente los primeros instruidos por la gracia que se convirtieron en los testigos oculares del Verbo no reduciendo este bien a ellos mismos, sino generando la misma gracia por transmisión para aquellos que vinieron después. Esta manifestación es posible por la presencia de Cristo que transforma al mismo hombre y que Gregorio llama economía de la Iglesia.

(15) El Esposo afirma yo amo a aquellos que me aman. Prov. 8, 17.

(16) Cf. Flp 3, 13.

(17) Cf. Gregorio de Nisa, Comentario al Cantar de los Cantares, edición preparada por Teodoro H. Martín-Lunas, Ediciones Sígueme, Salamanca 1993. En adelante citada CCEE I, 28.

(18) Cf. Meis A., La paradoja del hombre en el COMCANT Gregorio de Nisa y Orígenes, CO VII. 2.

(19) Langerbeck H., Gregorii Nysseni, In Canticum Canticorum, En: Jaeger W. (de.), GNOVI, Leiden

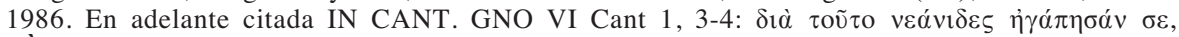

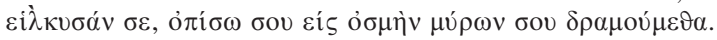

(20) CCEE I, 29.

(21) Ibídem 29.

(22) CCEE I, 28.

(23) Cf. Meis A., Orígenes y Gregorio de Nisa, "In Canticum" CO VI. 599-616. 
Gregorio comprende que las doncellas aspiran alcanzar a Cristo a causa de participar en la comunión, expresión de aquello que edifica el cuerpo de la Iglesia (24). Si hay comunión entre los diversos miembros de Cristo, es porque Dios nos comunica su unidad y la participación en esta unidad nos reúne en torno al buen olor de Cristo.

\section{b. La esposa}

Ella desea alcanzar el bien y se comporta como maestra experimentada (25), por eso se dice que en cierto modo es más perfecta, puesto que se acerca al Esposo cuando lo ha sentido por el perfume.

Por haberse acercado más a aquel que deseaba antes de que con sus ojos hubiese visto la hermosura de él, lo siente por el perfume. Y como por una propiedad del mismo color, distinta del buen olor, dice que ha conocido el perfume, el suave perfume de su ungüento que se llama nardo (26).

Se dice que ella lo ha conocido por el perfume, el suave perfume de su ungüento que se llama nardo. Por ello, se dirige a sus amigos diciendo: Mi nardo exhala su fragancia. Sin embargo, ¿ la esposa qué quiere decir con aquellas palabras?

Según Gregorio, ella se adentra en el proceso de intelección, por el cual comprende que el hombre no puede llegar a conocer, a palpar ni entender la misma divinidad. Por eso cuenta con el buen olor que forman a modo de ungüento las virtudes; por el cual aspirando su fragancia puede percibir con más sentido el buen olor de Él mismo (27). Es decir, el sentido una vez purificado percibe como si fuera olor del Esposo aquella fragancia que resulta de la mezcla de muchos y diversos aromas que huelen bien. Por aquella virtud divina y verdadera se nos hace visible al invisible, comprensible al incomprensible, de modo que operan la virtud y los olores aromáticos posibilitando el acceso al conocimiento del bien que supera toda inteligencia (28).

La esposa imita al Esposo a través de las virtudes, describiendo mediante imágenes la hermosura incognoscible. Por ello afirma que:

Cristo es el buen olor, la gracia suprema que está más allá de nuestra comprensión (29).

(24) Ibídem 50

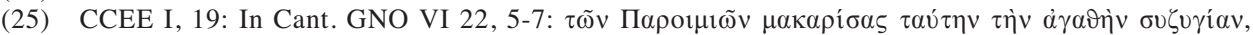

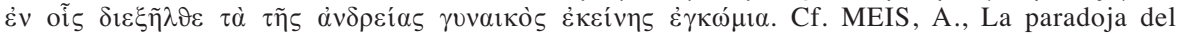
hombre en el COMCANT Gregorio de Nisa y Orígenes, CO VII, 2.

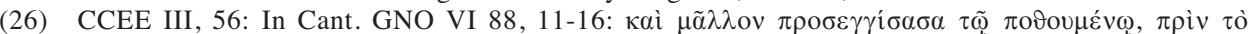

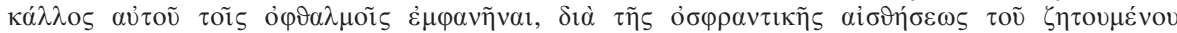

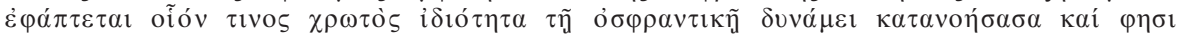

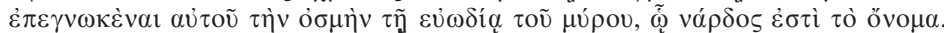

(27) Cf. CCEE III, 56.

(28) Cf. CCEE III, 57.

(29) CCEE III, 58: In Cant. GNO VI 91, 8-9: $\mu$

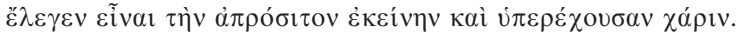


Entiende que el Esposo es fragante en sí mismo y es semejante al aire que se entrega a quien lo desea respirar. Para Gregorio este aire puede ser vivificante o mortífero según quién se dispone a recibirlo, es como un ungüento puesto ante un escarabajo o una paloma que puede producir diversos efectos. Es el caso del apóstol Pablo quien se saturaba de los buenos ungüentos (30), donde el buen olor de Cristo le daba vida (31).

Gregorio comprende que las virtudes no son un ejemplo de cualidades humanas que debemos esforzarnos por adquirir. Ellas manifiestan a Dios mismo que se ha entregado de ese modo a nosotros. De todas ellas, la caridad es clave porque instaura el orden del amor, es decir, todas las virtudes emanan de esa virtud perfecta. Sin embargo, no se nos da una clara visión del rostro de Dios, sino mediante el sentido del "olor" se nos da una percepción de su presencia en nosotros (32). En este sentido las virtudes son signos de la reciprocidad entre Dios y el hombre, donde la naturaleza humana es capaz de entregar a Dios sus propios dones (33). Las virtudes, una vez entradas en el interior del alma, muestran a través de una vida pura que ellas embellecen aquello que las contiene porque son embellecidas por aquel que las recibe (34). Gregorio comprende que el hombre no puede llegar a conocer la misma divinidad. Por eso la esposa cuenta con el buen olor que forman a modo de ungüento las virtudes, mediante las cuales puede percibir con más sentido la presencia de Cristo.

\section{EL PERFUME DEL UNGÜENTO DIVINO}

Mediante la imagen del perfume, Gregorio nos introduce a las líneas fundamentales de la Cristología, donde en Cristo (35) encontramos al mismo Dios que se hace accesible al hombre (36).

Cuando la esposa afirma:

Exquisitos de aspirar tus perfumes; tu nombre, un ungüento que se vierte (37).

(30) Muron (muron), palabra que los clásicos derivan de muro, fluir o de murra, aceite de mirra, se traduce la mayoría de las veces por mirra, también se traduce como ungüento. Cf. Vine Diccionario expositivo de palabras del Antiguo y del Nuevo Testamento. Editorial Caribe 2001, p. 653. Con la mirra se hace alusión al buen olor y a la plenitud del cielo. Cf. Lurker M., Diccionario de imágenes y símbolos de la Biblia. Ed. El Almendro 1994, p. 146.

(31) Cf. CCEE III, 58

(32) Cf. Canévet M., Dictionnaire de Spiritualité. Tomo VI, p. 996.

(33) Cf. Canévet M., Grégoire de Nysse et l'hermeneutique biblique. Études Augustiniennes. Paris 1983 , p. 343.

(34) Ibídem 344

(35) El culto perfecto fue realizado por Cristo, que se ofreció "a Dios en sacrificio de olor agradable", Ef 5, 2; Ex 29, 18; Sal 40, 7, es decir, su vida se consumió en ofrenda de olor agradable a Dios. Cf León-Dufour. Vocabulario de teología Bíblica Ed. Herder 1988, p. 687.

(36) Cf. Mateo-Seco L., La Cristología del In Canticum Canticorum de Gregorio de Nisa. Scrth 23 (1991) 189.

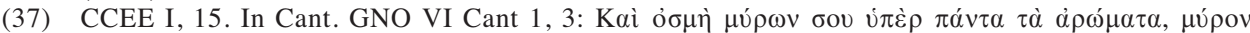

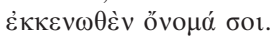


Gregorio advierte que este perfume es incapaz de evocar un olor conocido por el hombre porque se encuentra libre de la materia. Solo la inteligencia puede percibirlo a través de comparaciones llegando a aprender que toda sabiduría, que toda ciencia del hombre, toda vanidad contemplativa, no pueden equipararse al alimento divino. Incluso, la sabiduría humana más alta es pequeña ante la palabra de Dios, por ello el perfume del ungüento divino es mejor que la fragancia de cualquier aroma (38).

Por aroma, Gregorio entiende las virtudes: sabiduría, prudencia, temperancia, fortaleza... que cada persona las recibe según su propia capacidad. De esta manera, por el ejercicio de la libertad, cada uno a su modo es buen olor de Cristo, unos por moderación, otros por justicia o por fortaleza. Por ello, se puede comprender que el buen olor de Cristo se encuentra mezclado con muchos aromas. Siguiendo al profeta Habacuc, Dios es esta misma sabiduría, justicia o verdad, y el perfume de sus ungüentos nos ofrece una alegría incomparable si la relacionamos con los aromas que conocemos sobre la tierra (39). En el Cantar el perfume se identifica con el esposo, por eso las doncellas se enamoran y le siguen (40).

Gregorio afirma que la razón humana no tiene acceso a la virtud divina ni puede comprenderla. En la expresión tu nombre es ungüento que se vierte, da a entender que la naturaleza inmensa de Dios no puede ser comprendida de forma perfecta. El conocimiento humano y el significado de las palabras no pueden agotar lo que es propio de Dios. Nuestra razón, a través de vestigios y luces solo puede conjeturar, comprender por analogía. Según el Niseno, inventamos nombres para conocer el ungüento de la divinidad, pero el significado de las palabras no alcanza el ungüento en sí mismo. Con nombres teológicos solo indicamos pequeñas partículas del buen vapor del olor divino. Conocemos los vasos, los recipientes que contienen tal ungüento, pero ignoramos de qué naturaleza es su contenido (41).

Sin embargo, para Gregorio, Dios no es inalcanzable, sino que aun poseído, siempre sobrepasa al que ya lo posee (42). Intuye que Dios no es inaccesible, sino ilimitado. Por ello nuestra ignorancia sobre Dios se explica en cuanto Dios siendo infinito y la criatura finita, no podemos comprender su esencia. Esta es la caracterís-

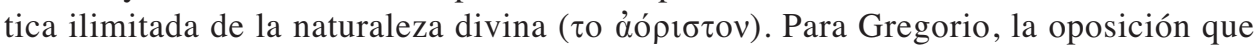
separa a Dios del mundo creado no recae en el binomio de lo inteligible-sensible, sino del Creador-creatura, en cuanto la creación es limitada y no puede agotar la esencia divina. El mundo podrá hablarnos de la sabiduría de Dios, pero no de lo que Él es realmente (43). Con esta expresión Gregorio desea subrayar la doctrina de la incognoscibilidad divina en cuanto el hombre por ser creado jamás comprenderá al ser divino increado. Al respecto se puede reconocer que Él es o que Él es el ser

(38) Cf. CCEE I, 26.

(39) Cf. CCEE I, 26.

(40) Cf. Mateos J., y Camacho F., Evangelio, figuras y símbolos. Ediciones El Almendro. Madrid 1992, p. 73.

(41) Cf. CCEE I, 27.

(42) Cf. Mateo-Seco L., ¿Progreso o inmutabilidad en la visión beatífica? Apuntes de la Historia de la Teología. En: Scripta Theologica 29 (1997) 21.

(43) Cf. Canévet M., Dictionnaire de Spiritualité. Tomo VI, pp. 984 y 985. 
verdadero, pero no se puede conocer su naturaleza (44). No hay nombre que pueda abarcar la naturaleza divina, nuestra razón solo puede acercarse mediante vestigios (45). Aquí Gregorio se encuentra próximo a Plotino, quien afirma que el amor carece de límite, porque el amado en sí mismo no tiene límite.

La novia del Cantar afirma que el perfume de la divinidad puede ser pensado aunque no definido. Ciertamente, el sentido de nuestras palabras no designará jamás el mismo perfume. Sin embargo, esos nombres que apuntan al conocimiento de Dios encuentran algunos restos de efluvio del perfume divino. Tomamos el ejemplo del frasco donde el perfume se expande, una vez expandido, el perfume no es aprehendido en su propia naturaleza, en su esencia. Entonces nos ayudamos del olor que habita en el frasco y que revela una especie de cualidad oscura, difícil de analizar para adivinar la naturaleza del perfume expandido. Tal es la enseñanza para Gregorio de esas palabras: el perfume mismo de la divinidad, ese que es por esencia, sobrepasa toda comprensión, toda idea, y de todos los milagros que observamos en la creación, son para nosotros ocasión de utilizar nombres análogos para una definición de Dios que podemos llamar sabiduría, todopoderoso, santo, bueno, bienaventurado, eterno, justo. En síntesis, Gregorio elabora una doctrina sobre la cual la esencia de Dios es ilimitada en su trascendencia, sin embargo la presencia de Dios puede ser percibida por el hombre a través de la comunicación que Él genera en su vida, a modo del ungüento perfumante (46).

\section{CONCLUSIÓN}

Gregorio de Nisa elabora una doctrina Cristológica comprendida desde la expresión del perfume a partir del itinerario de los personajes del Cantar, sostiene que las doncellas corren tras el olor perfumante del Esposo a causa de participar en la comunión como expresión de eclesialidad. Si hay comunión entre los diversos miembros de Cristo, es porque Dios nos comunica su unidad y de esta manera nos convertimos orgánicamente en su cuerpo, partícipes del mismo impulso vital.

La esposa, por su parte, cuenta con el buen olor que forman a modo de ungüento las virtudes. Con ello, Gregorio desea subrayar que el hombre es incapaz de poseer una clara visión del rostro de Dios y mediante el sentido del "olor" se nos regala una percepción de su presencia en medio nuestro.

A partir del simbolismo del perfume del Esposo, Gregorio nos permite comprender que a pesar de la incognoscibilidad de lo divino, al hombre le es permitido - a partir del olor que habita en el frasco- participar de la presencia de Dios. En este sentido podemos decir que la clave que unifica el método de Gregorio es la aceptación clara y total del misterio del Verbo encarnado. Es la persona de Cristo

(44) Cf. Canévet M., Grégoire de Nysse et l'hermeneutique biblique. Études Augustiniennes. Paris 1983 , pp. 251 y 252.

(45) Cf. Mateo-Seco L., La Cristología del In Canticum Canticorum de Gregorio de Nisa. Scrth 23 (1991) 181 .

(46) Cf. Daniélou J., Platonisme et théologie mystique, Doctrine spirituelle de saint Grégoire de Nysse, Paris 1954, pp. 209-258. 
en su doble naturaleza de increado y creado, de espíritu y carne, de invisible y visible, quien llega a ser el punto de referencia en la exégesis Nisena (47).

\title{
RESUMEN
}

El simbolismo del perfume, tanto en la tradición clásica y cristiana, se ha hecho poseedor de un valor inestimable porque desde tiempos antiguos se le ha relacionado como proximidad de la divinidad.

Gregorio de Nisa elabora una doctrina Cristológica comprendida desde la expresión del perfume a partir del itinerario de los personajes del Cantar, sostiene que las doncellas corren tras el olor perfumante del Esposo, a causa de participar en la comunión como expresión de eclesialidad. La esposa, por su parte, cuenta con el buen olor que forman a modo de ungüento las virtudes. Con ello, Gregorio comprende que el hombre es incapaz de poseer una clara visión del rostro de Dios y mediante el sentido del "olor" se nos regala una percepción de su presencia en medio nuestro. Es decir, Dios no es inalcanzable, sino que aun poseído, siempre sobrepasa al que ya lo posee, intuyendo que Dios no es inaccesible, sino solo ilimitado.

\begin{abstract}
The symbolism of perfume has been utilized in a highly valuable way to convey the idea of proximity to divinity, both in classical and Christian traditions.

Gregory of Nyssa elaborated a Christological doctrine from the concept of perfume, referring to the itinerary of the characters in the Song of Songs. He postulates that the young women, chasing after the perfumed aroma of the Bridegroom, are an image of participation in communion, an expression of ecclesiality. The bride, for her part, regards herself as possessing a "good scent" in the sense of an anointment with virtues. Thus Gregory understands that while we are incapable of possessing a clear vision of the face of God, through the sense of "smell" we are gifted with a perception of His presence in our midst. That is to say, God is not unreachable, but rather, even when possessed, He always goes beyond what is possessed, thus inferring that God is not inaccessible, but only unlimited.
\end{abstract}

(47) Cf. Gargano G., La teoria di Gregorio di Nissa sul Cantico dei Cantici. Indagine su alcune indicazioni di metodo esegetico, Orientalia Christiana. Analecta, Roma 1981, pp. 222-223. 